\title{
Dominasi Rosatom Rusia Dalam Pasar Energi Nuklir Global
}

\author{
Ahmad Saifudin Bukhari ${ }^{1}$
}

ahmadsbukhari@gmail.com

${ }^{1}$ Alumni Pascasarjana Prodi Magister Ilmu Politik Peminatan Hubungan Internasional, Universitas Padjadjaran. DOI: https://doi.org/10.22219/sospol.v7i1.10755

\begin{abstract}
This article aims to find out how Rosatom can dominate the nuclear energy market globally. In recent years, Rosatom dominates the world nuclear energy market. The Russian state-owned company has around 36 portfolios for building new nuclear power plants (NPP) in various countries. It also controls about $17 \%$ of the nuclear fuel market. This research uses descriptive qualitative research methods and the conceptual approach of neomerkantilism. Data collection is done by literature study. The results of this study argue that Rosatom can dominate the global nuclear energy market due to interference from the Russian state. Russia made Rosatom a state-owned company aimed at pursuing maximum revenues through nuclear energy exports for the improvement of the national economy as well as its political influence globally.
\end{abstract}

\begin{abstract}
Abstrak
Artikel ini memiliki tujuan untuk mengetahui bagaimana Rosatom dapat mendominasi pasar energi nuklir secara global. Dalam beberapa tahun terakhir, Rosatom mendominasi pasar energi nuklir dunia. Perusahaan milik negara Rusia ini memiliki sekitar 36 portofolio pembangunan Pembangkit Listrik Tenaga Nuklir (PLTN) baru di berbagai negara. Selain itu, Rosatom juga menguasai sekitar 17\% pasar bahan bakar nuklir. Penelitian ini menggunakan metode penelitian deskriptif kualitatif dengan pendekatan konsep neomerkantilisme. Teknik pengumpulan data dilakukan dengan cara studi literatur atau studi pustaka. Hasil dari penelitian ini menunjukkan bahwa Rosatom dapat mendominasi pasar energi nuklir global dikarenakan adanya pengaruh dan dukungan dari negara Rusia. Rusia menjadikan Rosatom sebagai perusahaan milik negara yang ditujukan untuk mengejar pendapatan sebesar-besarnya melalui ekspor energi nuklir demi peningkatan perekonomian nasional sekaligus pengaruh politiknya secara global.
\end{abstract}

\author{
Keywords \\ Energi Nuklir, PLTN, Rosatom, \\ Rusia.
}

\section{Article History}

Received December 31, 2019

Revised June 16, 2020

Accepted July 13, 2020

Published April 21, 2021

\section{Corresponding Author}

Ahmad Saifudin Bukhari

Jl. Bukit Dago Utara No.25, Bandung, Jawa Barat.

\section{Pendahuluan}

Nuklir pada perkembangannya tidak hanya digunakan sebagai senjata, tetapi juga sebagai sumber energi pembangkit listrik. Energi nuklir disebutkan sebagai salah satu energi yang sangat efisien dibandingkan dengan energi lainnya. Rata-rata kapasitas yang dihasilkan dari energi nuklir mencapai 91 persen, sedangkan gas alam hanya mencapai 50 persen, lalu batu bara hampir 59 persen, dan efisiensi tenaga angin hanya 32 persen (ESGI, 2015). Karena efisiensinya yang tinggi, saat ini banyak negara berkembang berusaha untuk memenuhi kebutuhan listriknya dengan energi nuklir. Tetapi karena kemampuan dan teknologi yang masih terbatas, negara-negara berkembang atau negara 'pendatang baru' dalam energi nuklir biasanya berusaha untuk mengembangkan program Pembangkit Listrik Tenaga Nuklir (PLTN) dengan bantuan perusahaan pemasok energi nuklir dari negara-negara maju.

Rosatom merupakan salah satu perusahaan pemasok PLTN dan bahan bakar energi nuklir terbesar di dunia. Rosatom menguasai sekitar 17\% pasar bahan bakar energi nuklir dunia (Rosatom, 2018, p. 9). Selain itu, perusahan milik negara Rusia ini menerima banyak pesanan PLTN dari berbagai negara, terutama negara-negara berkembang. Menurut laporan terakhir, 
Rosatom memiliki sekitar 36 portofolio pembangunan PLTN baru di berbagai negara. Nilai dari total portofolio tersebut mencapai \$133,2 miliar (Rosatom, 2018, p. 52).

Jumlah pesanan portofolio yang dimiliki Rosatom tersebut sangat besar jumlahnya jika dibandingkan dengan perusahaan-perusahaan energi nuklir lain. Misalnya EDF, perusahaan listrik Prancis hanya memiliki 5 portofolio pesanan luar negeri. Lalu KEPCO dari Korea Selatan dan Toshiba-Westinghouse masing-masing hanya memiliki 4 portofolio. Kemudian yang paling sedikit perusahaan energi nuklir Tiongkok China National Nuclear Company (CNNC) hanya memiliki 2 portofolio (Rosatom, 2017, p. 29).

Besarnya jumlah portofolio yang dimiliki Rosatom ini merupakan hasil dari upaya perluasan pasar yang gencar mereka lakukan dalam sepuluh tahun terakhir. Sejak didirikan pada tahun 2007 oleh pemerintah Rusia, tujuan dari perusahan ini adalah untuk mengembangkan industri energi nuklir secara lebih luas dengan meningkatkan ekspansi pangsa pasar Pembangklit Listrik Tenaga Nuklir (PLTN) dalam lingkup domestik dan juga global (Mukhatzhanova, 2007). Rosatom saat ini telah menguasai sekitar 67\% pasar PLTN dunia dengan sejumlah portofolio pembangunan PLTN di 12 negara, yaitu Rusia, Tiongkok, India, Belarus, Banglades, Turki, Iran, Armenia, Mesir, Uzbekistan, Hungaria, dan Finlandia (Rosatom, 2018, pp. 41, 52).

Penelitian tentang perluasan pasar dan ekspor energi nuklir Rusia sebelumnya sudah pernah dikaji oleh Sim (2017) dan Schepers (2019). Sim (2017) mengkaji ekspor energi nuklir sebagai upaya diversifikasi ekonomi yang dilakukan Rusia. Menurut temuannya, Industri nuklir diidentifikasi sebagai salah satu faktor strategis untuk mempelopori diversifikasi ekonomi Rusia agar tidak bergantung terhadap hidrokarbon. Industri nuklir dan pengayaan uranium merupakan ekspor teknologi tinggi yang meningkatkan vitalitas sektor manufaktur Rusia. Namun, Diversifikasi ini tidak hanya didorong oleh pertimbangan ekonomi, tetapi juga terdapat pertimbangan politik bagi pemimpin negara Rusia, yaitu untuk menjadi instrumen legitimasi dan untuk memuaskan aspirasi populer tentang ekonomi modern. Sementara itu, Scheper (2019) mengkaji status, prospek, dan implikasi dari ekspor energi nuklir Rusia. Hasil dari penelitian Scheper menunjukkan bahwa kehadiran Rosatom yang mengglobal dalam teknologi nuklir dan pasar energi didasarkan pada strategi ekspor terpadu yang diperkuat oleh proyek-proyek masa lalu dan pendekatan khusus untuk mengundang para pendatang baru dalam mengembangkan nuklir. Tetapi hal ini menimbulkan kekhawatiran terhadap keamanan nuklir global karena semakin banyak negara akan mempunyai teknologi nuklir dengan kemampuan dan pengetahuan nuklir yang belum kuat.

Berbeda dengan penelitian-penelitian tersebut, penelitian ini bertujuan untuk mengetahui bagaimana Rosatom mendominasi pasar energi nuklir dunia. Penelitian ini lebih menekankan Rosatom sebagai perusahaan milik negara yang tujuan dan aktivitas bisnisnya dipengaruhi langsung oleh pemerintah Rusia. Oleh karena itu, pendekatan yang digunakan dalam penelitian ini adalah konsep tentang ekonomi nasionalisme seperti neomerkantilisme.

Istilah merkantilisme pertama kali disebutkan oleh Viktor de Riqueti, marquis de Mirabeau pada tahun 1763. Lalu istilah ini dipopulerkan oleh Adam Smith sejak tahun 1776 dalam bukunya "Wealth of Nation". Merkantilisme sendiri adalah sebuah doktrin ekonomi politik yang berkembang di kawasan Eropa Barat pada masa lampau, dimana pembuat keputusan dan pedagang (merchant) berusaha untuk meningkatkan kekayaan melalui tindakan negara. Seperti yang dijelaskan oleh Mirabeu bahwa merkantilisme adalah sebuah konsep ekonomi politik dimana negara dan pemerintah melakukan intervensi secara langsung terhadap kegiatan ekonomi dengan melindungi pedagang domestik (Magnusson, 2015, p. 217). Hal yang hampir sama juga diungkapkan oleh McCusker yang mendefinisikan merkantilisme sebagai seperangkat kebijakan, regulasi, dan hukum yang berkembang antara abad ke-16 dan abad ke-18 untuk mendukung kenaikan negara-negara Eropa dengan menundukkan perilaku ekonomi privat untuk tujuan nasional (F. T. Yu, 2019, p. 176). 
Dalam perspektif merkantilisme, penting bagi sebuah negara untuk mengejar kekayaan dan kesejahteraannya. Sebuah negara harus mencapai surplus perdagangan dan pembayaran agar mendapatkan keuntungan dan kekayaan. Karena dalam perpektif ini, kekayaan dan kesejahteraan merupakan zero-sum game dalam kompetisi global, dimana keuntungan bagi satu pihak berarti kerugian bagi pihak lainnya (Gilpin, 2001, p. 78). Sehingga kekayaan suatu negara hanya bisa meningkat dengan mengorbankan atau merugikan yang lainnya. Dengan demikian, kebijakan merkantilisme berusaha untuk memperkuat negara secara ekonomi dan politik untuk merugikan negara lain (Magnusson, 1994, p. 4).

Peningkatan kekayaan dan kesejahteraan oleh negara merkantilis dilakukan dengan cara perluasan pasar dan peningkatan perdagangan global. Kedua hal tersebut dilakukan negara untuk meningkatkan ekspor dan juga sekaligus menekan impor. Keuntungan yang didapatkan dari jumlah ekspor yang lebih tinggi adalah logam mulia yang didapatkan menjadi lebih banyak. Maka dengan logam mulia yang dimiliki lebih banyak tersebut negara akan merasa kekakayaan dan kesejahteraannya semakin meningkat (Deliarnov, 2006, pp. 22-23).

Neomerkantilisme berbeda dengan merkantilisme klasik yang sudah dijelaskan sebelumnya, meskipun dalam beberapa prinsip masih memiliki kesamaan. Keduanya sama-sama memiliki asumsi bahwa pentingnya negara mengontrol perekenomian mereka dan memaksimalkan kekayaan ekonomi. Perbedaannya adalah neomerkantilisme dalam beberapa prinsip masih dapat menerima pandangan dari liberalisme yang merupakan penantang dari merkantilisme. Meskipun demikian, neomerkantilisme lebih dekat dengan perspektif realisme (Kirshner, 2009, p. 38; Ziegler, 2010, pp. 76-78).

Pandangan neomerkantilisme terhadap tatanan internasional memiliki kesamaan dengan realisme, yaitu melihatnya sebagai sesuatu yang bersifat anarki, dimana negara sebagai entitas kompetitif selalu berusaha memaksimalkan kekuatan relatif untuk menjaga keamanan dan kedaulatan serta mengejar ambisi mereka lebih luas. Neomerkantilisme tidak hanya memberi perhatian terhadap negara sebagai aktor dominan, tetapi juga pada perusahaan-perusahaan besar dan pengaturan perdagangan yang digunakan negara untuk meningkatkan posisi internasional mereka. Neomerkantilisme dalam hal ini berupaya untuk menjelaskan bagaimana negara akan memaksimalkan kekayaan ekonomi sebagai metode 'sadar diri' untuk meningkatkan posisi relatif mereka dalam sistem internasional. Negara-negara yang menganut konsep ini menggunakan perangkat pemerintah untuk mencoba mengatasi atau membatasi tekanan pasar yang dapat menghambat pengembangan perusahaan-perusahaan yang dianggap penting bagi kekuatan negara. Neomerkantilisme juga berasumsi bahwa negara akan meminimalkan hambatan pada pilihan mereka dengan berusaha mengendalikan investasi asing dan aliran keuangan lainnya atau juga dengan cara membatasi kerentanan terhadap hambatan ekonomi eksternal (Ziegler, 2010, p. 76).

Sementara itu dalam pespektif liberalisme menekankan pentingnya memperluas kapasitas produktif melalui perluasan perdagangan, mengurangi hambatan (barriers) pada transaksi ekonomi, dan memaksimalkan manfaat dalam efisiensi dan harga (keunggulan komperatif). Perspektif ini melihat persaingan ekonomi sebagai positif-sum game dan interdependensi, yang berarti tidak membatasi ketergantungan adalah strategi yang tepat untuk memaksimalkan keuntungan ekonomi (Kirshner, 2009, p. 38). Pandangan ini dapat diterima sebagian oleh neomerkantilisme, tetapi sebagian yang lainnya sangat bertentangan. Neomerkantilisme dapat menerima wawasan liberalisme tentang pentingnya kapasitas produktif dan perluasan pasar, tetapi bertentangan tentang hubungan yang tepat antara negara dan pasar. Neomerkantilisme sangat kritis terhadap asumsi liberalisme yang melihat bahwa kepentingan pribadi konsumen individu akan memaksimalkan kekayaan negara. Bagi neomerkantilisme, pedoman negara atau bahkan dengan kepemilikan atas perusahaan secara keseluruhan atau pun sebagian merupakan hal yang penting untuk memastikan bahwa prilaku individu dan perusahaan sesuai dengan kepentingan nasional (Ziegler, 2010, pp. 77-78). Oleh karena itu, neomerkantilisme memiliki asumsi bahwa kontrol negara atas ekonomi adalah strategi yang tepat dan memang penting untuk mencapai tujuan 
tertinggi dari memaksimalkan kekuatan negara, dan mengurangi kerentanan yang menyertai integrasi ke dalam ekonomi global (Ziegler \& Menon, 2014, p. 20).

Besarnya peran negara dalam ekonomi dapat disebut sebagai bentuk nasionalisme ekonomi. Tetapi meskipun demikian, neomerkantilisme tidak semata-mata menolak pasar, mereka berusaha untuk melindungi kepentingan negara dengan mengendalikan cara kerja nasional dan internasional (Hettne, 1993, pp. 237-238). Demi tujuan tersebut, negara neomerkantilis berusaha untuk mengendalikan "komando tertinggi" ekonomi, terutama dalam sektor terbesar dan paling strategis melalui perusahaan-perusahaan milik negara sepenuhnya atau sebagian dengan bertindak sebagai agen negara yang didukung dalam berbagai cara (Ziegler, 2010, p. 78).

Karena atas dasar itu Rusia menguasai sektor energi yang memiliki pengaruh paling besar terhadap perekonomian nasional. Rusia mengusainya melalui perusahaan-perusahaan milik negara seperti Gazprom, Rosneft dalam sektor energi hidrokarbon dan Rosatom dalam sektor energi nuklir. Rusia melalui Rosatom berusaha untuk memenuhi kebutuhan energi nasional dan juga mencari keuntungan sebesar-besarnya dengan ekspansi pasar secara luas di berbagai belahan dunia. Hal ini bertujuan untuk meningkatkan jumlah ekspor agar pendapatan nasional mereka bertambah dan perekonomian meningkat.

\section{Metode}

Dalam penelitian ini, penulis menggunakan metode deskriptif-kualitatif. Metode kualitatif adalah metode yang digunakan untuk mencari tahu tentang makna dan proses terhadap permasalahan yang akan diteliti (Mason, 2002, pp. 1-2). Dalam arti yang lebih luas, metode kualitatif merujuk pada pengumpulan data dan teknik analisis yang mengandalkan pengumpulan dan analisis data non-numerik (Lamont, 2015, p. 78). Maka metode kualitatif yang dimaksud dalam penelitian ini adalah untuk mendeskripsikan tentang makna dan proses dari dominasi pasar energi nuklir yang dilakukan Rosatom, terutama sebagai pemasok PLTN. Untuk dapat menjelaskan hal tersebut penelitian ini menggunakan perspektif neomerkantilisme. Pengumpulan data dalam penelitian ini dilakukan dengan cara studi pustaka, yaitu mengumpulkan data primer maupun sekunder yang tidak secara langsung melakukan wawancara, tetapi data didapatkan dari berbagai sumber seperti buku, laporan, jurnal ilmiah, artikel daring dan berbagai sumber dari internet yang relevan untuk mendukung penelitian ini.

\section{Hasil dan Pembahasan}

Bagian ini menjelaskan tentang bagaimana Rosatom dapat mendominasi pasar energi nuklir dunia dan motivasi Rusia dibalik itu. Penjelasan tentang hal tersebut diawali dengan menggambarkan strategi energi nuklir Rusia, lalu perluasan pasar ekspor yang dilakukan Rosatom, hingga motivasi Rusia terhadap dominasi pasar yang dilakukan Rosatom.

\section{Strategi Energi Nuklir Rusia}

Sebelum berdirinya Rosatom, industri energi nuklir Rusia berada dibawah tanggung jawab Kementerian Energi Atom. Kemudian setelah mendirikan Rosatom pada tahun 2007, seluruh industri nuklir Rusia, termasuk energi nuklir, senjata nuklir, armada kapal pemecah es bertenaga nuklir, hingga lembaga penelitian nuklir dikendalikan oleh Rosatom. Rosatom mengelola lebih dari 300 perusahaan dan organisasi yang terlibat dalam semua tingkat bidang senjata nuklir dan rantai produksi listrik. Ini termasuk kegiatan siklus bahan bakar nuklir dari awal hingga akhir seperti penambangan uranium, konversi, pengayaan dan fabrikasi bahan bakar, kegiatan yang berkaitan dengan konstruksi, operasi dan penonaktifan PLTN dan kegiatan siklus back-end seperti pemrosesan ulang bahan bakar nuklir bekas dan pengelolaan limbah radioaktif (Rosatom, 2016a, p. 12).

Sebagai perusahaan milik negara, Rosatom sepenuhnya berada dibawah kendali pemerintah Rusia. Direktur, anggota pengawas hingga tujuan strategis dari Rosatom ditentukan 
oleh Presiden Rusia. Adapun tujuan yang ingin dicapai pemerintah Rusia saat pertama kali mendirikan Rosatom adalah membangun 10 unit PLTN baru di Rusia pada tahun 2015 dan memenangkan 20\% dari pasar nuklir global (Mukhatzhanova, 2007). Kemudian pada tahun 2010, pemerintah Rusia meningkatkan target pasar nuklir mereka menjadi 25\% (Sim, 2017, p. 184). Dengan memperluas pasarnya, maka itu berarti ekspor energi nuklir juga akan meningkat dan pendapatan yang didapatkan dari ekspor juga akan meningkat. Target peningkatan pendapatan yang ingin dicapai Rosatom dari ekspor energi nuklir adalah 65\% di tahun 2030 (Rosatom, 2016b, p. 5).

Tujuan dan target besar Rusia tersebut membuat Rosatom menjadi sangat gencar mempromosikan produk energi nuklirnya secara global. Untuk melakukan hal itu, Rosatom membentuk "Rosatom International Network" yang membuka kantor di berbagai kawasan di dunia. Tugas mereka adalah untuk mendukung kegiatan divisi Rosatom di pasar luar negeri, mencari peluang bisnis baru, mempromosikan produksi dan layanan dari perusahaan-perusahaan industri nuklir Rusia, memberikan bantuan dalam menciptakan aliansi bisnis yang efektif, dan melakukan fungsi-fungsi lain dalam bidang bisnis internasional atas perintah Rosatom dan divisi-divisinya. Adapun kantor-kantor regional Rosatom tersebut berada di Prancis, Ceko, Hungaria, Ukraina, Singapura, Kazakhtan, India, Tiongkok, Uni Emirat Arab, Afrika Selatan, dan Amerika Serikat (Rosatom, n.d.-b).

Selain itu, untuk mendukung Rosatom sebagai pemasok PLTN dan bahan bakar nuklir terbesar di dunia, Rosatom menguasai pertambangan-pertambangan uranium di beberapa negara. Pertambangan uranium tersebut dikelola oleh anak perusahaan Rosatom yaitu Uranium One. Perusahaan ini beroperasi di Kazakhtan, Amerika Serikat, dan Tanzania. Di Kazakhtan, Uranium One menjalin kerjasama Joint Venture (JV) dengan perusahaan-perusahaan pertambangan lokal seperti Southern Mining Chemical Company LLC (kepemilikan 70\% di pertambangan uranium Akdala dan Inkai selatan), JV Karatau dengan kepemilikan 50\%, JV Akbastau dengan kepemilikan 50\%, JV Zarechnoye dengan kepemilikan 49,98\%, dan JV Khorasan-U dengan kepemilikan 30\%). Lalu di Amerika Serikat, Uranium One menguasai pertambangan uranium Willow Creek di daerah Johnson dan Campbell, negara bagian Wyoming. Kemudian yang terakhir di Tanzania, Uranium One memiliki pengembangan proyek pertambangan uranium sungai Mkuju yang berlokasi di Selatan Tanzania (Uranium1, n.d.).

Penguasaan Rosatom atas seluruh produksi dan siklus bahan bakar nuklir dengan rantai pasokan yang terintegrasi dan jaringan kantor yang luas memudahkannya dalam memberikan pelayanan terhadap para "pendatang baru" yang ingin memulai program energi nuklir mereka dan juga ke negara-negara yang sudah memiliki program nuklir untuk layanan tertentu. Salah satu bentuk pelayanan Rusia yang mencakup keseluruhan kebutuhan calon pelanggannya adalah "Rosatom Integrated Solution". Solusi terintegrasi ini memberikan akses ke seluruh lini produk dan layanan dari Rosatom sepanjang masa layanan PLTN. Beberapa layanan dan solusi yang terkandung dalam paket pelayanan tersebut adalah solusi energi, pengembangan infrastruktur nuklir, solusi industrial, suplai bahan bakar dan back-end, pengembangan sumber daya manusia, operasi dan pemeliharaan, dan penerimaan publik (Rosatom, n.d.-a).

Tidak hanya dengan memberikan paket solusi yang terintegrasi, Rosatom juga memberikan tawaran solusi dalam pembiayaan proyek energi nuklir. Solusi pembiayaan tersebut berupa pinajaman bank, kredit ekspor, pinjaman keuangan negara, dan investasi penanaman modal. Bantuan pembiayaan ini disesuaikan dengan model kontrak bisnis yang disepakati bersama. Rosatom dalam ekspor produk energi nuklirnya menawarkan beberapa model bisnis yang fleksibel, yang dapat disesuaikan dengan kebutuhan dan kemampuan pelanggannya. Model bisnis yang ditawarkan adalah Built, Own, Operate (BOO), Built, Own, Operate, Transfer (BOOT), dan TurnkeyEngineering, Procurement, Construction (EPC) (Sokolov, 2013).

Model bisnis BOO biasanya dilakukan dengan negara-negara pendatang baru yang kemampuan nuklirnya masih terbatas, contohnya seperti Turki dalam proyek PLTN Akkuyu. 
Sedangkan dalam model bisnis turnkey, negara pelanggan harus sudah memiliki kemampuan yang cukup dalam mengoperasikan PLTN secara mandiri. Hal ini dikarenakan Rosatom dalam model bisnis ini hanya merancang dan membangun reaktor nuklir, sedang pengoperasiannya akan dijalankan oleh negara pelanggan. Contoh yang menggunakan model bisnis ini adalah Iran, Bangladesh, Hungaria dan Finlandia (Schepers, 2019, p. 4).

Selain itu semua, Rusia memiliki nilai tambah lain dibandingkan dengan industri nuklir negara lainnya. Rosatom merupakan satu-satunya pemasok yang mengambil kembali bahan bakar nuklir bekas dari pelanggannya di luar negeri. Hal ini adalah insentif tambahan bagi negara-negara pendatang baru yang tidak memiliki infrastruktur siklus bahan bakar nuklir yang diperlukan untuk menangani bahan bakar bekas. Tentunya hal ini juga sangat menguntungkan para pelanggan pendatang baru karena memudahkan pekerjaan mereka dalam pemeliharaan PLTN (Schepers, 2019, p. 3).

\section{Dominasi dan Ekspansi Pasar Oleh Rosatom}

Berbagai strategi dan keunggulan yang dimiliki Rosatom memudahkannya dalam melakukan ekspansi pasar. Rosatom berhasil memperkuat kehadirannya secara global dan mendominasi pembangunan PLTN baru di banyak negara. Laporan tahunan Rosatom tahun 2017 menyebutkan bahwa pendapatan internasional mereka adalah sebesar $\$ 6,1$ miliar, dimana $\$ 2,5$ miliar berasal dari pembangunan PLTN dengan sejumlah portofolio pesanan luar negeri senilai \$ 133 miliar. Jumlah pendapatan tersebut meningkat 17,1\% dari tahun sebelumnya (Rosatom, 2017, p. 28). Lalu pada tahun 2018, pendapatan internasional Rosatom meningkat menjadi $\$ 6,5$ miliar. Peningkatan tersebut salah satunya didorong oleh bertambahnya jumlah pesanan luar negeri untuk konstruksi PLTN, keuntungan yang didapatkan dari konstruksi PLTN di luar negeri pada tahun 2018 adalah \$2,8 miliar (Rosatom, 2018, p. 54). Saat ini Rosatom sedang mengerjakan 36 proyek unit PLTN di 12 negara, yaitu di Tiongkok, India, Belarus, Banglades, Turki, Iran, Armenia, Mesir, Uzbekistan, Hungaria, dan Finlandia (Rosatom, 2018, p. 52).

Ekspansi pasar yang dilakukan oleh Rosatom telah berhasil membuat mereka mendominasi pasar energi nuklir global, terutama dalam konstruksi PLTN. Rosatom saat ini telah menguasai sekitar 67\% pasar PLTN dunia (Rosatom, 2018, p. 41). Seperti yang sudah disebutkan sebelumnya, Rosatom memiliki 36 portofolio konstruksi PLTN baru di berbagai negara. Sementara perusahaan energi nuklir lainnya hanya memiliki sedikit portofolio konstruksi PLTN. Misalnya EDF, perusahaan listrik Prancis hanya memiliki 5 portofolio pesanan luar negeri. Lalu KEPCO dari Korea Selatan dan Toshiba-Westinghouse masing-masing hanya memiliki 4 portofolio. Kemudian yang paling sedikit perusahaan energi nuklir Tiongkok China National Nuclear Company (CNNC) hanya memiliki 2 portofolio (Rosatom, 2017, p. 29).

Kesuksesan Rosatom dalam mendominasi pasar energi nuklir dunia ini tidak dapat terlepas dari dukungan yang dapatkan dari pemerintah Rusia. Hal ini dilakukan melalui dukungan diplomasi. Dukungan ini dapat disalurkan selama kunjungan ke luar negeri oleh Presiden dan pejabat pemerintah lainnya, dan juga ketika menyambut delegasi asing ke Rusia. Hal ini dilakukan dengan memasukkan kerjasama tentang penggunaan energi nuklir secara damai dalam agenda selama kunjungan, menyebutkannya dalam pidato publik atau menandatangani Nota Kesepahaman tentang masalah tersebut. Misalnya yang dilakukan Presiden Putin dalam pidatonya dalam pertemuan Rusia ASEAN Summit tahun 2016. Dalam pertemuan tersebut, Putin mengajak negara-negara ASEAN untuk meningkatkan kerjasama di sektor energi dan bahan bakar, yaitu kerjasama dalam pembangunan PLTN. Putin mengungkapkan bahwa Rusia siap untuk membantu pembangunan PLTN di negara-negara ASEAN (Sputnik, 2016). Lalu contoh lainnya seperti yang dilakukan oleh Wakil Perdana Menteri Rusia Dmitry O. Rogozin ketika berkunjung ke Indonesia pada tahun 2014. Rogozin pada saat itu menawarkan Indonesia kerjasama energi nuklir untuk mengembangkan proyek energi nuklir nasional (Mohamad, 2014). 
Diplomasi yang dilakukan Rusia tersebut berhasil membuat negara-negara ASEAN tertarik untuk mengembangkan energi nuklir. Beberapa negara seperti Myanmar, Kamboja, Laos dan Filipina telah menandatangani MoU kerjasama energi nuklir dengan Rusia dan Rosatom untuk tujuan pengembangan program energi nuklir nasional mereka (Reuters, 2015; Sputnik, 2015; WNN, 2016, 2017). Meskipun belum sampai kepada kontrak portofolio PLTN baru, tetapi MoU tersebut di masa yang akan datang dapat mengarah kepada kerjasama untuk pembangunan PLTN.

Tidak hanya di Kawasan Asia Tenggara, Rusia juga melakukan diplomasi energi nuklir di Kawasan Timur-Tengah. Misalnya dengan Iran, Rusia sangat berperan dalam memajukan proyek energi nuklir Iran melalui proyek PLTN Busher meskipun banyak ditentang oleh Barat. Selain itu, Rusia juga berhasil mengajak negara-negara Timur-Tengah lainnya menjalin kerjasama energi nuklir untuk membangun PLTN di negara mereka. Negara-negara tersebut adalah Turki, Mesir, Jodania, Algeria, dan Arab Saudi. Rusia menjalin kerjasama energi nuklir dengan Turki sejak tahun 2010, dimana dalam kerjasama tersebut mereka sepakat untuk membangun emapat unit PLTN di Akkuyu. Lalu dengan Jordania pada tahun 2013 yang direncanakan akan membangun PLTN Qasr Amra dengan bantuan 49\% pendanaan dari Rosatom. Pada tahun 2014, Rusia menjalin kerjasama energi nuklir dengan Mesir dan juga Jordania. Kedua negara sepakat dengan Rusia untuk membangun PLTN pertama mereka yang akan dikerjakan oleh Rosatom. Selanjutnya di tahun 2015, Rusia juga menjalin kerjasama energi nuklir dengan Arab Saudi. Arab Saudi berencana untuk membangun PLTN dengan total kapasitas hingga hingga 17 GW pada tahun 2032 (Giuli, 2017, pp. 2-3).

Jumlah pesanan PLTN Rosatom diperkirakan akan terus meningkat seiring dengan diplomasi energi nuklir yang terus dilakukan oleh pemerintah Rusia. Diplomasi tersebut menghasilkan pertambahan jumlah perjanjian 'kerangka kerja' antar pemerintah yang memberikan dasar hukum untuk negosiasi di bidang-bidang khusus seperti energi nuklir. Negara-negara yang baru menandatangani perjanjian bilateral dengan Rusia adalah Aljazair, Bolivia, Kamboja, Kuba, Ghana, Nigeria, Paraguay, Arab Saudi, Sudan, Tajikistan, Tunisia, Uni Emirat Arab (UEA) dan Zambia. Selain itu juga ada kerjasama yang dilakukan antar lembaga negara dalam bentuk nota kesepahaman yang belum memiliki status hukum. Beberapa mengarah pada perjanjian kerangka kerja, atau kontrak pembangunan PLTN dan Pusat Sains dan Teknologi Nuklir (Schepers, 2019, p. 2).

\section{Motivasi Rusia}

Jika merujuk pada konsep neomerkantilisme, motivasi utama Rusia dalam perluasan pasar energi nuklir adalah untuk mengejar kekayaan dan kesejahteraan sebesar-besarnya dengan meningkatkan ekpor energi nuklir. Energi nuklir merupakan sektor strategis dalam perekonomian Rusia. Sehingga penting bagi Rusia untuk menguasai sektor tersebut melalui perusahaan milik negara Rosatom untuk dapat memaksimalkan keuntungan ekonomi yang bisa didapatkan dari sektor tersebut.

Salah satu alasan mengapa Rusia harus memaksimal kentungan ekonominya dari sektor energi nuklir adalah karena Rusia tidak dapat terus bergantung terhadap ekspor energi hidrokarbon. Rusia hingga saat ini masih sangat bergantung terhadap ekspor minyak dan gas, yang jumlah ekspor keduanya mencapai 60 persen dari total ekspor Rusia dan menyumbang lebih dari 30 persen pendapatan produk domestik bruto (PDB) (Depersio, 2019). Terus bergantung terhadap ekspor minyak bumi dan gas alam sangat beresiko bagi perekonomian nasional mereka, karena kedua komoditas energi tersebut sering mengalami volatilitas. Jika harga dari kedua komoditas tersebut turun secara tiba-tiba, maka pendapatan Rusia juga akan mengalami penurunan dan bahkan dapat berakibat pada defisit perdagangan. Oleh karena itu, perluasan pasar energi nuklir yang dilakukan oleh Rosatom merupakan upaya jangka panjang Rusia dalam mengurangi ketergantungan ekonominya terhadap ekspor minyak dan gas. Seperti yang tercantum dalam dokumen Strategi Energi 2030, Rusia berusaha mengurangi ketergantungannya pada ekspor 
minyak dan gas. Ekspor kedua komoditas energi tersebut diimbangi dengan peningkatan ekspor energi alternatif, yaitu energi nuklir dan energi terbaharukan (Government of the Russian Federation, 2010, pp. 15-22).

Selain mengejar keuntungan ekonomi, ada kepentingan politik yang juga ingin dicapai oleh Rusia, yaitu mengejar power atau kekuatan dan pengaruh dalam dunia internasional. Bahkan menurut organisasi lingkungan hidup Bellona menyebutkan bahwa pengembangan industri nuklir yang dilakukan oleh Rosatom lebih memperhatikan kepentingan politik dibandingkan ekonomi. Menurut mereka, Rusia berusaha membuat hubungan ketergantungan negara lain melalui energi nuklir (Carbonnel, 2013).

Dengan kontrak kerjasama pembangunan PLTN melalui Rosatom, Rusia memang dapat menciptakan hubungan ketergantungan negara-negara pelanggannya terhadap negaranya sendiri, terutama bagi negara-negara berkembang. Karena produk PLTN yang dijual Rosatom adalah produk paket manufaktur yang menyediakan barang dan jasa yang terintegrasi dalam layanan 'rosatom integrated solution'. Sehingga negara pelanggan akan tergantung terhadap Rosatom mulai dari pembangunan PLTN, penyediaan dan pengolahan bahan bakar nuklir hingga perawatan dan pengawasannya. Kemudahan pembiayaan melalui pinjaman yang diberikan Rosatom juga dapat menambah ketergantungan negara pelanggan.

Ketergantungan yang diciptakan Rusia ini dapat memperkuat kehadirannya di negara lain. Maka hal itu juga berarti pengaruh Rusia terhadap negara pelanggan PLTN Rosatom akan semakin meningkat. Lalu Rusia secara tidak langsung juga akan memperkuat posisinya dalam politik internasional. Penting bagi Rusia untuk memperkuat posisinya di dunia internasional untuk dapat mengimbangi kekuatan dari Amerika Serikat dan Tiongkok.

\section{Kesimpulan}

Penguasaan Rusia atas sektor energi nuklir melalui perusahaan milik negara Rosatom merupakan bentuk kebijakan neomerkantilisme. Artinya Rusia melalui Rosatom memonopoli industri energi nuklir domestik dan melakukan ekspansi pasar ekspor secara global dengan masif agar mendapatkan keuntungan ekonomi yang besar. Tujuannya adalah untuk meningkatkan kesejahteraan dan kekayaan bagi negara. Selain itu juga untuk menjaga keamanan ekonomi dan energi dengan mendiversifikasi ekspor produk dan pasar energi. Hal ini sangat penting dijaga oleh Rusia mengingat ketergantungannya yang besar terhadap ekspor minyak bumi dan gas alam yang rentan mengalami volatilitas. Selain kepentingan ekonomi, terdapat pula kepentingan politik yang dikejar Rusia terhadap dominasi Rosatom. Secara politis, Rusia menginginkan penguatan posisinya sebagai negara besar dalam sistem internasional. Hal ini penting bagi Rusia mengingat agar pengaruh politiknya meningkat, negara tersebut perlu melakukan perluasan ekspor produk energi nuklirnya guna menciptakan ketergantungan negara-negara lain. Kedua motivasi tersebut, yakni ekonomi dan politik berhasil mendorong Rosatom mendominasi energi nuklir global, khususnya pasar PLTN. Sehingga keberhasilan Rosatom ini tidak dapat dilepaskan dari pengaruh dan dukungan pemerintah Rusia sendiri. Pemerintah Rusia sangat berperan dalam membuat strategi ekspansi yang dilakukan oleh Rosatom, lalu juga memberikan dukungan yang sangat besar melalui diplomasi energi nuklir yang dilakukan secara bilateral maupun multilateral.

\section{Referensi}

Carbonnel, A. de. (2013). Russian nuclear ambition powers building at home and abroad. Retrieved December 23, 2019, from Rosatom website: https://rosatom.ru/en/press-centre/industryin-media/145-russian-nuclear-ambition-powers-building-at-home-andabroad/?sphrase_id $=217455$

Deliarnov. (2006). Ekonomi Politik. Jakarta: Erlangga.

Depersio, G. (2019). How does the price of oil affect Russia's economy? Retrieved December 23, 2019, from Investopedia website: 
https://www.investopedia.com/ask/answers/030315/how-does-price-oil-affect-russiaseconomy.asp

ESGI. (2015). Know the Efficiency of Nuclear Power. Retrieved November 21, 2019, from Energy Services Group International website: https://www.esgi.net/2015/05/08/knowefficiency-of-nuclear-power-energy-staffing-jobs /

Gilpin, R. (2001). Global Political Economy: Understanding The International Economic Order. In Princeton University Press. New Jersey: Princeton University Press.

Giuli, M. (2017). Russia's nuclear energy diplomacy in the Middle East : why the EU should take notice. European Policy Centre, (February), 1-4. Retrieved from http://aei.pitt.edu/84489/1/pub_7455_russiasnuclearenergydiplomacy.pdf

Government of the Russian Federation. (2010). Energy Strategy of Russia For The Period Up To 2030 (Vol. 6). Moscow: Institute of Energy Strategy.

Hettne, B. (1993). The Concept of Neomercantilism. In L. Magnussen (Ed.), Mercantilist Economics (pp. 235-255). https://doi.org/10.1007/978-94-011-1408-0_10

Kirshner, J. (2009). Realist political economy: Traditional themes and contemporary challenges. In M. Blyth (Ed.), Routledge Handbook of International Political Economy (IPE): IPE as a Global Conversation (pp. 36-47). https://doi.org/10.4324/9780203881569

Lamont, C. (2015). Research Methods in International Relations. London: SAGE Publication.

Magnusson, L. (1994). Eli Heckscher and Mercantilism An Introduction. Uppsala.

Magnusson, L. (2015). The political economy of mercantilism. The Political Economy of Mercantilism, 1-230. https://doi.org/10.4324/9781315694511

Mason, J. (2002). Qualitative Researching (2nd ed.). Retrieved from http://www.amazon.co.uk/Qualitative-Researching-Jennifer-Mason/dp/0761974288

Mohamad, A. (2014). Rusia Tawarkan Reaktor Nuklir dan Industri Pesawat Terbang. Retrieved December 22, 2019, from Jakarta Greater website: https://jakartagreater.com/ru/

Mukhatzhanova, G. (2007). Russian Nuclear Industry Reforms: Consolidation and Expansion. Retrieved November 21, 2019, from James Martin Center for Nonproliferation Studies website: https://www.nonproliferation.org/russian-nuclear-industry-reforms-consolidationand-expansion/

Reuters. (2015). Russia to help Cambodia build capacity for nuclear power. Retrieved December 22, 2019, from Reuters website: https://www.reuters.com/article/us-cambodia-russianuclear-idUSKBNOTFOW220151126

Rosatom. (n.d.-a). Rosatom Integrated Solution. Retrieved from Rosatom website: https://www.rosatom.ru/en/integrated-offer/

Rosatom. (n.d.-b). Rusatom International Network. Retrieved December 20, 2019, from Rosatom website: https://rosatom.ru/en/global-presence/the-international-businessdepartment/rusatom-international-network-pe-moscow/

Rosatom. (2016a). Performance of State Atomic Energy Corporation Rosatom in 2016: Public Annual Report. Moscow.

Rosatom. (2016b). Rosatom Key Fact. Moscow.

Rosatom. (2017). Performance of State Atomic Energy Corporation Rosatom in 2017: Public Annual Report. Moscow.

Rosatom. (2018). State Atomic Energy Corporation Rosatom Performance in 2018. Moscow.

Schepers, N. (2019). Russia's Nuclear Energy Exports: Status, Prospects and Implications.

Sim, L. C. (2017). Economic diversification in Russia: Nuclear to the rescue? In S. Mahroum \& Y. Al-Saleh (Eds.), Economic Diversification Policies in Natural Resource Rich Economies (pp. 175-202). https://doi.org/10.4324/9781315660981

Sokolov, Y. A. (2013). Multiple Approaches on Supporting Nuclear Program Development and Contracting on NPPs. Retrieved December 20, 2019, from IAEA website: https://www.iaea.org/NuclearPower/Downloadable/Meetings/2013/2013- 02-11-02-14- 
TM-INIG/11.sokolov.pdf

Sputnik. (2015). Russia and Myanmar Signed a Memorandum on Nuclear Energy Cooperation. Retrieved December 22, 2019, from Sputnik News website: https://sputniknews.com/business/201506181023529862/

Sputnik. (2016). Russia Ready to Propose ASEAN New Nuclear Electrical Power Plants - Putin. Retrieved from Sputnik News website: https://sputniknews.com/business/201605201039956970-asean-nuclear-power-plants/

Uranium1. (n.d.). Our Operations. Retrieved from Uranium One: A Rosatom Global Mining Company website: http://www.uranium1.com/our-operations/\#home

WNN. (2016). Russia and Laos Plan Nuclear Cooperation. Retrieved December 22, 2019, from World Nuclear News website: http://www.world-nuclear-news.org/NP-Russia-and-Laosplan-nuclear-cooperation-1504164.html

WNN. (2017). Russia and Philippines agree to nuclear cooperation. Retrieved December 22, 2019, from World Nuclear News website: http://www.world-nuclear-news.org/Articles/Russiaand-Philippines-agree-to-nuclear-cooperatio

Yu, F. T. (2019). Contemporary Issues in International Political Economy. In F.-L. T. Yu \& D. S. Kwan (Eds.), Contemporary Issues in International Political Economy (pp. 175-196). https://doi.org/10.1007/978-981-13-6462-4

Ziegler, C. E. (2010). Neomercantilism and energy Interdependence: Russian strategies in East Asia. Asian Security, 6(1), 74-93. https://doi.org/10.1080/14799850903472029

Ziegler, C. E., \& Menon, R. (2014). Neomercantilism and Great-Power Energy Competition in Central Asia and the Caspian. Strategic Studies Quarterly, 8(2), 17-41. Retrieved from http://www.au.af.mil/au/ssq/digital/pdf/summer_2014/ziegler.pdf 